\title{
Mesenchymal stem cell contact promotes CCN1 splicing and transcription in myeloma cells
}

\author{
Julia Dotterweich ${ }^{1}$, Regina Ebert ${ }^{1}$, Sabrina Kraus ${ }^{2}$, Robert J Tower ${ }^{3}$, Franz Jakob ${ }^{1+}$ and Norbert Schütze ${ }^{1 *+}$
}

\begin{abstract}
CCN family member 1 (CCN1), also known as cysteine-rich angiogenic inducer 61 (CYR61), belongs to the extracellular matrix-associated CCN protein family. The diverse functions of these proteins include regulation of cell migration, adhesion, proliferation, differentiation and survival/apoptosis, induction of angiogenesis and cellular senescence. Their functions are partly overlapping, largely non-redundant, cell-type specific, and depend on the local microenvironment. To elucidate the role of CCN1 in the crosstalk between stromal cells and myeloma cells, we performed co-culture experiments with primary mesenchymal stem cells (MSC) and the interleukin-6 (IL-6)-dependent myeloma cell line INA-6. Here we show that INA-6 cells display increased transcription and induction of splicing of intron-retaining CCN1 pre-mRNA when cultured in contact with MSC. Protein analyses confirmed that INA-6 cells co-cultured with MSC show increased levels of CCN1 protein consistent with the existence of a pre-mature stop codon in intron 1 that abolishes translation of unspliced mRNA. Addition of recombinant CCN1-Fc protein to INA-6 cells was also found to induce splicing of CCN1 pre-mRNA in a concentration-dependent manner. Only full length CCN1-Fc was able to induce mRNA splicing of all introns, whereas truncated recombinant isoforms lacking domain 4 failed to induce intron splicing. Blocking RGD-dependent integrins on INA-6 cells resulted in an inhibition of these splicing events. These findings expand knowledge on splicing of the proangiogenic, matricellular factor CCN1 in the tumor microenvironment. We propose that contact with MSC-derived CCN1 leads to splicing and enhanced transcription of CCN1 which further contributes to the translation of angiogenic factor CCN1 in myeloma cells, supporting tumor viability and myeloma bone disease.
\end{abstract}

Keywords: CCN1, Multiple myeloma, Mesenchymal stem cells, Splicing

\section{Background}

$\mathrm{CCN}$ family member 1 (CCN1) belongs to the modular extracellular matrix (ECM)-associated CCN protein family named according to three prototypic members (cysteinerich angiogenic inducer $61 \mathrm{CYR61/CCN1}$, connective tissue growth factor CTGF/CCN2, and nephroblastoma overexpressed NOV/CCN3). Proteins share $30-50 \%$ primary sequence homology and are organized into four discrete domains with sequence relationships to insulin-like growth factor binding proteins (IGFBPs), the von Willebrand factor type C (vWC) repeat domain, the thrombospondin type I repeat (TSR) domain, and a carboxy-terminal (CT) domain containing a cysteine-knot motif [1]. These immediate early gene-encoded proteins are regulated by growth factors and hormones (e.g. transforming growth factor-beta (TGF $\beta$ ),

\footnotetext{
* Correspondence: n-schuetze.klh@uni-wuerzburg.de

${ }^{\dagger}$ Equal contributors

'Orthopedic Center for Musculoskeletal Research, Orthopedic Department, University of Würzburg, Brettreichstrasse 11, 97074 Würzburg, Germany
} Full list of author information is available at the end of the article tumor-necrosis factor alpha (TNF $\alpha)$ ), 1,25-dihydroxyvitamin D3, and mechanical forces [2-4]. Their functions are partly overlapping, yet appear to be mostly non-redundant, and are expressed in a cell-type specific manner dependent on the local microenvironment. CCN1 shows complex functionality due to specific interactions with a variety of binding partners including integrins and proteoglycans [5]. CCN1 knockout is embryonically lethal in many pups due to alteration of chorioallantoic fusion, whereas most perish due to hemorrhage between E11.5 and E14.5 with only a very few being born alive, but dying within $24 \mathrm{~h}$ [6]. The multiple functions of CCN1 include regulation of cell migration, adhesion, proliferation, differentiation and survival/ apoptosis, cellular senescence and ECM protein synthesis [4,7-10]. Through these diversity of functions, CCN1 modulates important biological processes including developmental processes, angiogenesis and tissue regeneration, and plays a role in pathological conditions such as wound healing, vascular diseases, inflammation, fibrosis and tumor 
development [10,11]. CCN1 has been shown to act both as an oncogene, e.g. in mammary cancer, and as a tumor suppressor $[10,12,13]$. The importance of CCN1 in tumorigenesis originates from its diverse molecular functions which influence tumor development and metastasis by modulating angiogenesis, epithelial mesenchymal transition (EMT), and anoikis resistance [14]. Expression of CCN1 in tumors is characterized by deregulated protein levels, either of full length or truncated isoforms, whose diversity is expanded by post-translational processing, as well as by alternative splicing $[15,16]$. In the case of breast cancer tissue, alternative splicing of intron 3 has been linked to tumor progression and was regulated in tumor cells by exposure to hypoxic and acidic microenvironments [16-18]. In order to explain the apparent mismatch between the number of genes $(25,000)$ versus the number of proteins that exist in humans $(90,000)$, the last decade has seen extensive research about mechanisms that underlie the complexity of the proteome such as posttranslational modification mechanisms and alternative splicing. Splicing regulatory factors are currently under intensive research as "oncogenic alternative splicing switches" which may serve as promising new treatment targets in oncology [16]. In this context alternative splicing as a means of producing a biological diversity of CCN proteins has been discussed [15].

Multiple Myeloma (MM) is a B-cell malignancy characterized by clonal proliferation of a terminally-differentiated plasma cell, and is associated with immunoglobulin light chain or heavy chain production. MM is the second most common hematological malignancy and is accompanied by a high mortality and morbidity, despite recent progress in treatment modalities $[19,20]$. A major devastating complication of this disease is myeloma bone disease, which is associated with increased mortality and is driven by interaction between myeloma cells and cells of the bone marrow microenvironment, leading to imbalanced bone remodeling [21]. Bone metabolism is orchestrated by a complex interaction between bone-forming mesenchymal stem cells (MSC) and their osteogenic offspring (osteoblasts/osteocytes), and monocyte-derived osteoclasts. Bone formation is driven by at least three major osteogenic pathways, namely parathyroid hormone 1 receptor (PTH1R), bone morphogenetic proteins (BMP) and their receptors, and the wnt/ frz/LRP5/6 pathway, along with sclerostin (SOST) and dickkopf-1 (DKK-1) which act as potent inhibitors of the wnt pathway [22]. Osteoclast development is dependent on colony-stimulating factors and receptor activator of NFKB ligand (RANKL) produced by osteoblasts [23]. Myeloma cells also produce RANKL or RANKL-inducing molecules thereby initiating the classical vicious cycle of tumorinitiated osteolysis [24]. Myeloma bone disease dissociates bone resorption from bone formation and disintegrates the cooperation between osteogenic differentiation and angiogenesis. This supports myeloma progression and results in the inhibition of bone regeneration [25]. Bone regeneration is inhibited by myeloma-associated secreted inhibitors like DKK-1, secreted frizzled related proteins 2 and 3 (SFRP2/3), SOST and activin which interfere with osteogenic differentiation pathways [26,27]. Conversely, osteoblasts, for largely unknown reasons, can inhibit myeloma cell growth, as has been shown for MM treatment with the proteasome inhibitor bortezomib, which supports osteoblast function via enhanced vitamin D receptor signaling $[28,29]$. Antibody and antagonist-based neutralization strategies of osteogenic inhibitors (DKK1, activin, SOST) are currently under development for the management of myeloma bone disease [30-33].

Myeloma cells are dependent on and influenced by stromal support. MSC have been described both as efficient supporters for myeloma cell growth and survival, and as potent disease modifiers that can inhibit MM cell growth [34]. MSC from MM patients exhibited intrinsic defects in osteogenic differentiation, which may permissively support MM expansion [35]. Moreover, overproduction of e.g. GDF15 by MSC, as seen in MM patients, is a powerful protective mechanism for MM cells and is linked to patient survival [36]. In contrast, intra-bone injection of MSC inhibited MM progression in preclinical settings [37]. Hence, there is a huge clinical need to unravel the multiple effects induced by tumor-MSC interactions and to demonstrate their impact on the course of disease.

In the present study, we investigated the expression of CCN1 in myeloma cells under conditions of a tumorsupportive microenvironment. We describe for the first time that myeloma cells display intron retention in CCN1 mRNA, followed by splicing of all introns, enhanced transcription and consecutive translation upon contact with MSC. We also demonstrate that this effect can be exerted by recombinant $\mathrm{CCN} 1$ protein which further enhances myeloma cell viability.

\section{Results}

\section{Contact with MSC induces CCN1 pre-mRNA splicing, transcription, and CCN1 protein production in INA-6 multiple myeloma cells}

To elucidate the role of CCN1 in the crosstalk between stromal cells and myeloma tumor cells, we performed co-culture experiments with primary MSC and the interleukin-6 (IL-6)-dependent myeloma cell line INA-6 [38]. Using intron-4 spanning primers (CCN1 4-5), INA6 cells co-cultured with MSC expressed two alternate mRNA forms of different sizes (321 bp, 206 bp) compared to INA-6 control cells, which showed only a single variant (321 bp) (Figure 1A). Sequence analyses confirmed that the two variants represented the spliced (206 bp) and unspliced (321 bp) forms of CCN1 mRNA. To evaluate if splicing is restricted to intron 4, additional 


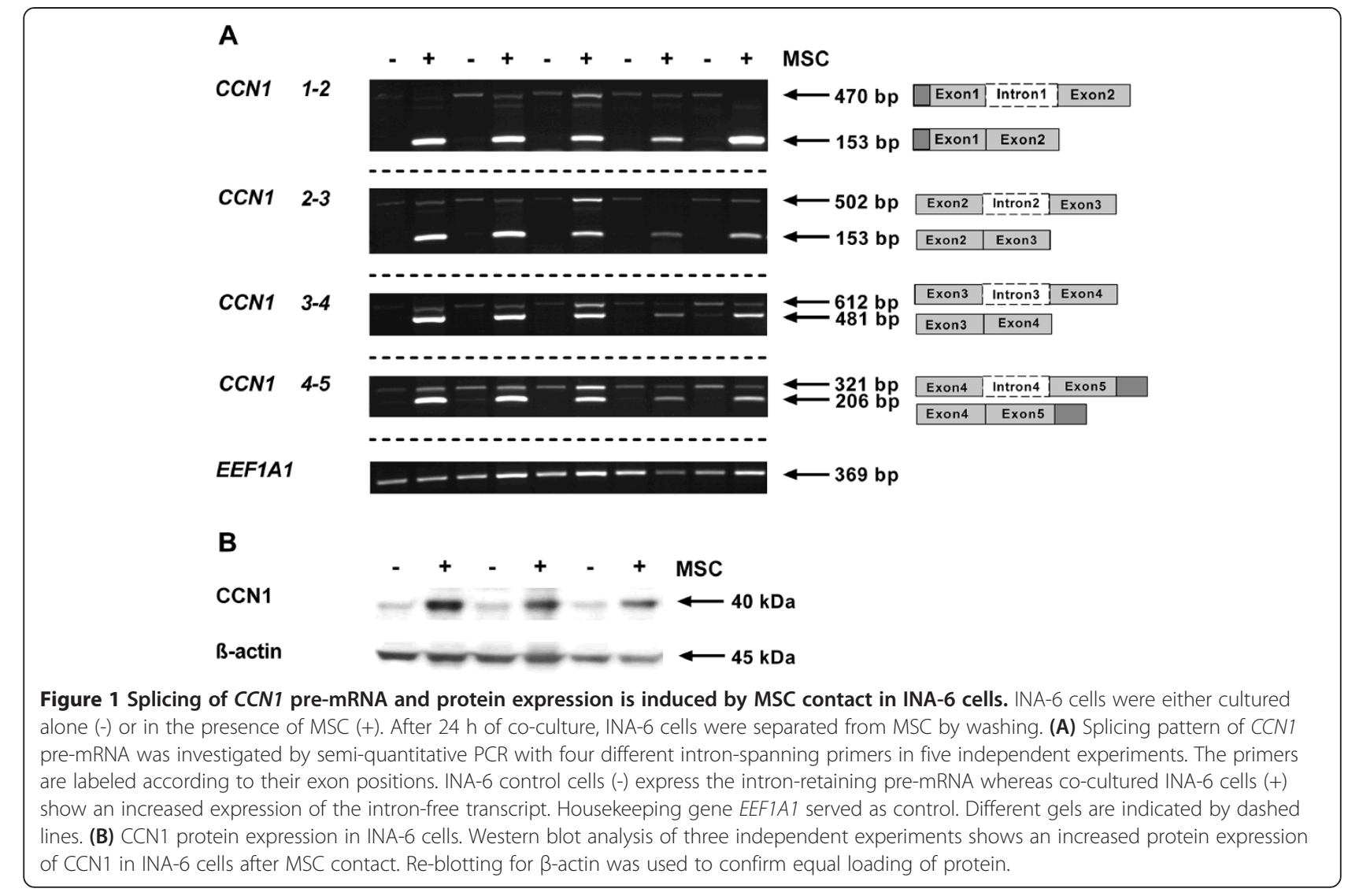

primer pairs were designed to span the remaining three exon-intron transitions (Table 1). In each case, INA-6 control cells expressed the intron-retaining pre-mRNA, whereas INA-6 cells in contact with MSC expressed both the intron-retaining pre-mRNA and, to a greater extent, the intron-free isoform (Figure 1A). Overall, this pattern indicates that each intron of CCN1 is affected by splicing upon contact with MSC. This was additionally confirmed by long-range PCR, as the combination of the 5'-primer CCN 1-2 and the 3'-primer CCN 4-5 showed two bands representing intron-retained and intron-free CCN1 mRNA (data not shown). To elucidate if transcription of CCN1 is enhanced in INA-6 cells after MSC contact, qPCR analyses were performed. CCN1 mRNA expression in INA-6 cells co-cultured with MSC increased significantly by 5.3 fold (SD: $1.7-14.2$ : $\mathrm{p}<0.001$ calculated with REST [39]), with a high donor variability (2.4 to 17.3 fold), compared to control cells (data not

Table 1 Primer sequences and conditions of semi-quantitative PCR

\begin{tabular}{|c|c|c|c|c|c|}
\hline \multirow{2}{*}{$\begin{array}{l}\text { Gene product } \\
C C N 11-2\end{array}$} & \multicolumn{2}{|c|}{ Primer 5'-3' sequence } & \multirow{2}{*}{$\begin{array}{c}\text { Annealing temperature }\left({ }^{\circ} \mathrm{C}\right) \\
56\end{array}$} & \multirow{2}{*}{$\begin{array}{c}\text { Length of PCR product (bp) } \\
470\end{array}$} & \multirow{2}{*}{$\frac{\text { mRNA isoform }}{\text { Intron-retained }}$} \\
\hline & Reverse & TCACCCTTCTCCACTTGACC & & & \\
\hline & Forward & AGTCCTCGTTGAGCTGCTTG & & 153 & Intron-free \\
\hline \multirow[t]{2}{*}{ CCN1 2-3 } & Reverse & ACCGCTCTGAAGGGGATCT & 56 & 502 & Intron-retained \\
\hline & Forward & GGGACACAGAGGAATGCAG & & 153 & Intron-free \\
\hline \multirow[t]{2}{*}{ CCN1 3-4 } & Reverse & GGCAGACCCTGTGAATATAA & 50 & 612 & Intron-retained \\
\hline & Forward & CAGGGTTGTCATTGGTAACT & & 481 & Intron-free \\
\hline \multirow[t]{2}{*}{ CCN1 4-5 } & Reverse & CAACCCTITACAAGGCCAGA & 54 & 321 & Intron-retained \\
\hline & Forward & TGGTCTTGCTGCATTTCTTG & & 206 & Intron-free \\
\hline \multirow[t]{2}{*}{ EEFIA1 } & Reverse & CTGTATTGGATTGCCACG & 54 & 369 & \\
\hline & Forward & AGACCGTTCTTCCACCACTG & & & \\
\hline
\end{tabular}


shown). As intron-retaining CCN1 sequence revealed a pre-mature stop codon in intron 1 (Additional file 1: Figure S1), translation of full-length $\mathrm{CCN} 1$ protein, as well as truncated isoforms, could be excluded in INA- 6 control cells since exon 1 only encodes for the signal peptide, whereas intron-free CCN1 mRNA expressed by INA-6 cells after MSC contact should be able to translate the full-length protein. To analyze protein expression of CCN1, INA-6 control cells, as well as MSC cocultured INA- 6 cells, were investigated by western blot using the polyclonal antibody CYR61 H-78, raised against amino acids located in the "hinge-region". Western blot analyses demonstrated that INA-6 cells cocultured with MSC showed a $345 \%$ increase in CCN1 protein levels in contrast to INA-6 control cells cultured alone (Figure 1B). As only a small number of MSC reside within the bone marrow, we additionally performed co-culture experiments with INA-6 and osteoblasts, generated by incubating MSC with osteogenic differentiation media for 14 days. CCN1 4-5 primers confirmed a similar splicing pattern in INA-6 cells obtained after coculture with MSC (data not shown).

\section{Exogenous stimulation by recombinant CCN1-Fc protein induces $C C N 1$ pre-mRNA splicing and transcription in INA-6 cells in a concentration-dependent manner}

Hirschfeld et al. previously described the splicing of intron 3 in CCN1 pre-mRNA in association with breast cancer progression as an oxygen- and $\mathrm{pH}$-regulated event $[17,18]$. In our case, neither incubation in hypoxic $\left(1 \% \mathrm{O}_{2}\right)$ nor acidic conditions led to splicing of CCN1 in INA-6 cells (data not shown). Furthermore, indirect coculture experiments with trans-well inserts (data not shown), as well as experiments with MSC-derived conditioned media (MSC-CM) (Additional file 2: Figure S2), was not sufficient to induce CCN1 mRNA splicing in INA-6 cells. It has previously been shown that exogenous stimulation using recombinant $\mathrm{CCN} 1$ protein induced endogenous CCN1 production [40]. To determine if this effect was mediated through splicing, we investigated if splicing of CCN1 pre-mRNA occurs after treatment with recombinant protein. Although CCN1 is highly expressed by MSC [8], native protein concentration may rapidly diminish in solution due to aggregation on MSC cell surface or cell culture dishes. Therefore, exogenous stimulation of INA-6 cells was performed by using an Fc-tagged recombinant $\mathrm{CCN} 1$ protein (CCN1$\mathrm{Fc}$ ), which is more stable in solution. INA-6 cells were incubated with varying concentrations of recombinant CCN1-Fc protein for $24 \mathrm{~h}$ and analyzed by PCR with CCN1 intron-4 spanning primers (CCN1 4-5). Results show that treatment with $\mathrm{CCN} 1-\mathrm{Fc}$ induced splicing of CCN1 pre-mRNA in a concentration-dependent manner, as represented by an increased amount of intron-free
RNA isoform compared to total CCN1 mRNA (Figure 2). Incubation with $1 \mu \mathrm{g} / \mathrm{ml} \mathrm{CCN1-Fc} \mathrm{increased} \mathrm{the} \mathrm{percent}$ of CCN1 mRNA in its intron-free form from $10 \%$, observed before recombinant protein addition, to $40 \%$ after protein addition. This increased prevalence of intron-free CCN1 mRNA was further enhanced to 70\% intron-free mRNA by incubation with $2.5 \mu \mathrm{g} / \mathrm{ml}$ of recombinant protein. To evaluate if splicing is not only concentration dependent, but also time dependent, we performed time course experiments after $4 \mathrm{~h}, 8 \mathrm{~h}$ and $24 \mathrm{~h}$. Concentrations of CCN1-Fc which showed small to medium splicing activity after $24 \mathrm{~h}$ incubation were used to allow detection of enhanced splicing. Splicing plateaued within $4 \mathrm{~h}$ of incubation with recombinant protein concentrations as low as $0.05 \mu \mathrm{g} / \mathrm{ml}$ (Additional file 3: Figure S3), and remained consistent for up to $72 \mathrm{~h}$ after stimulation with CCN1-Fc (data not shown). Splicing of CCN1 pre-

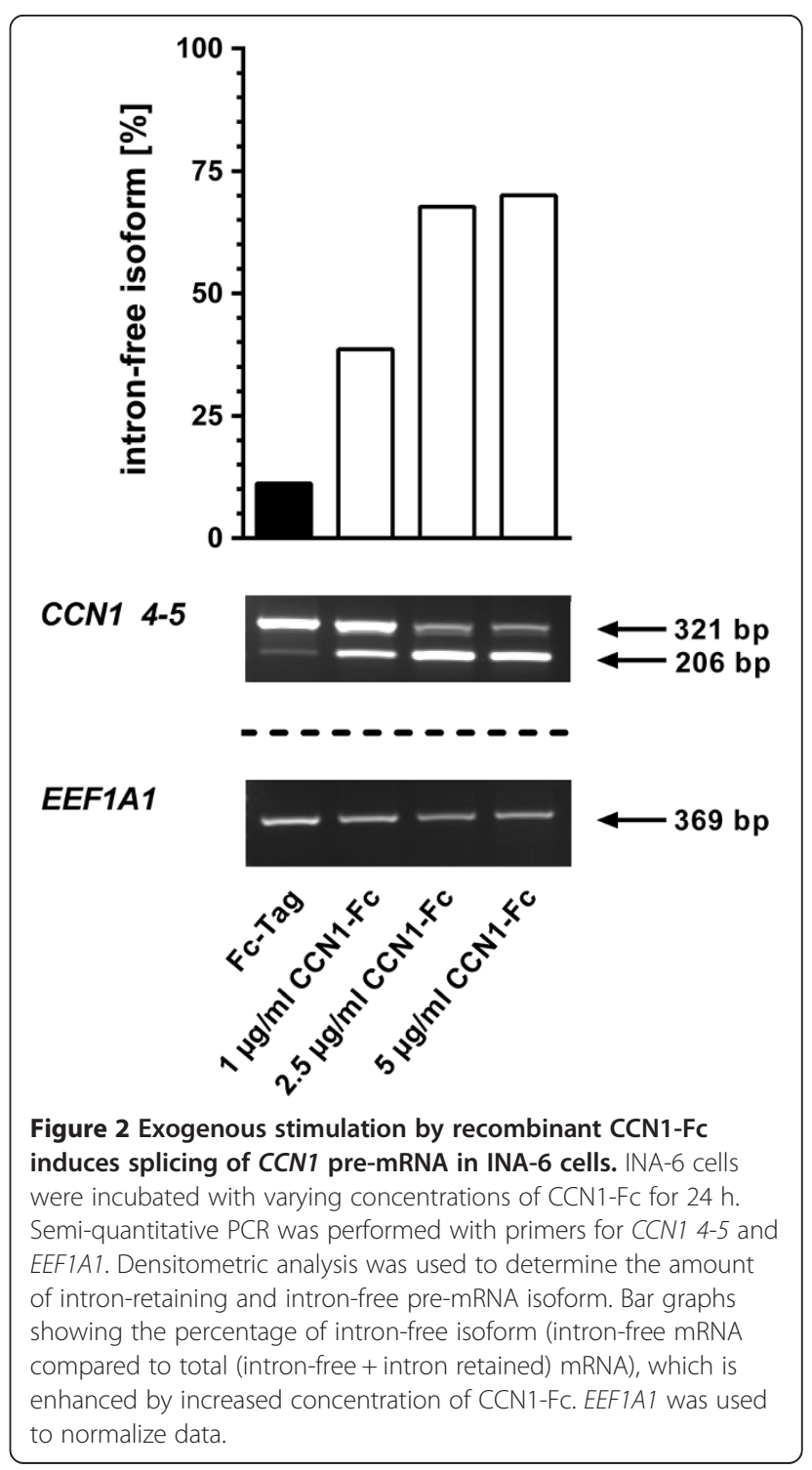


mRNA appears to be a rapid, concentration-dependent event in response to $\mathrm{CCN} 1$ protein stimulation. To determine changes at the transcription level of CCN1 mRNA in response to CCN1-Fc treatment, we measured overall intensity of bands obtained with intron-4 spanning primers by semi-quantitative PCR and densitometric analyses. Relative to mRNA expression in Fc-Tag treated control cells, incubation with $1 \mu \mathrm{g} / \mathrm{ml}$ or $5 \mu \mathrm{g} / \mathrm{ml} \mathrm{CCN1-Fc} \mathrm{led} \mathrm{to} \mathrm{a} 1.8$ fold increased expression of CCN1 (Additional file 4: Figure S4A). Similar results were obtained by $\mathrm{qPCR}$ with a second intron-4 spanning primer pair. Treatment with $1 \mu \mathrm{g} / \mathrm{ml}$ CCN1-Fc enhanced CCN1 mRNA expression by 1.4 fold, $2.5 \mu \mathrm{g} / \mathrm{ml} \mathrm{CCN1-Fc} \mathrm{led} \mathrm{to} \mathrm{a} 2.5$ fold enhanced gene expression, which diminished to 2.1 fold after stimulation with $5 \mu \mathrm{g} / \mathrm{ml} \mathrm{CCN1-Fc} \mathrm{in} \mathrm{comparison} \mathrm{to} \mathrm{Fc-Tag} \mathrm{control}$ (Additional file 4: Figure S4B).

\section{Domain 4 of CCN1-Fc is involved in inducing CCN1 pre-mRNA splicing}

To characterize which domains of $\mathrm{CCN} 1$ are involved in stimulating mRNA intron splicing, we incubated INA-6 cells with full length $\mathrm{CCN} 1-\mathrm{Fc}$, as well as truncated isoforms comprising domain 1 (CCN1-Fc 1), domains 1 and 2 (CCN1-Fc 1-2) or domains 1-3 (CCN1-Fc 1-3). Only the full length $\mathrm{CCN1}-\mathrm{Fc}$ was able to induce the splicing of CCN1 mRNA for all introns while induction with truncated CCN1-Fc showed only limited splicing of introns 1 and 2 (Figure 3A), highly suggestive that domain 4, also known as the cysteine-knot containing module (CT), is necessary for the induction of splicing of all introns. Because CCN protein functions are mediated mainly by integrin binding [41] and because domain 4 contains several integrin binding sites, we next blocked integrin-binding activity on INA-6

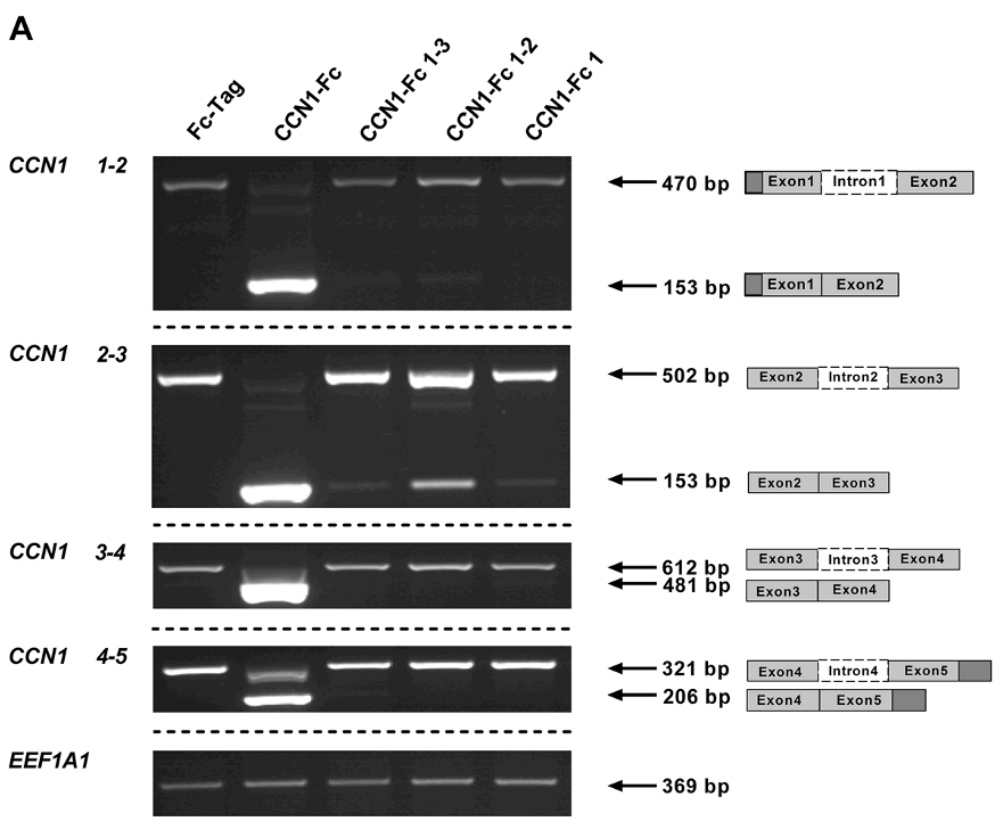

B

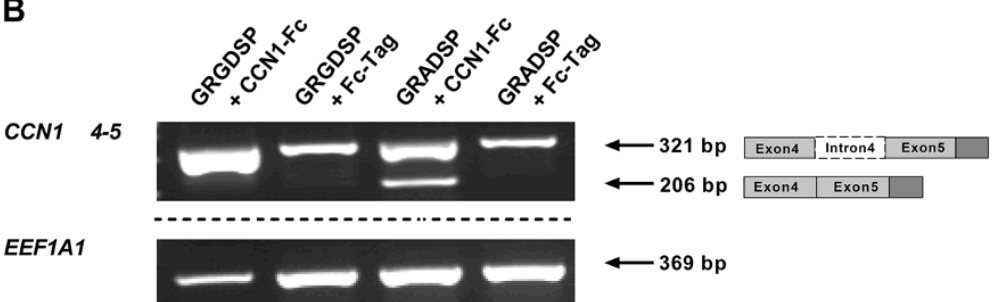

Figure 3 Domain 4 of CCN1-Fc is required to induce CCN1 pre-mRNA splicing. (A) INA-6 cells were incubated with either $2.5 \mu \mathrm{g} / \mathrm{ml}$ recombinant CCN1-FC full-length protein, or an equivalent amount of truncated CCN1 isoforms (CCN1-FC 1-3, CCN1-FC 1-2, and CCN1-FC 1). Semi-quantitative PCR with intron-containing CCN1 primers showed that exposure to truncated CCN1 proteins comprising domains 1, 1-2, or 1-3 did not induce complete CCN1 mRNA splicing. (B) Splicing of CCN1 pre-mRNA induced by $2.5 \mu \mathrm{g} / \mathrm{ml}$ full-length CCN1-FC was reversed by GRGDSP peptide $(50 \mathrm{\mu g} / \mathrm{ml}$ in culture media) but not by addition of the control peptide GRADSP. One representative experiment out of three is shown. 
cells by pre-incubation with GRGDSP peptide, followed by the addition of full length CCN1-Fc. Incubation with GRGDSP peptide inhibited splicing of intron 4 in contrast to the control peptide GRADSP, which failed to inhibit splicing of intron-free mRNA (Figure 3B). Comparing integrins that are able to bind RGD motif in their ligands [42] with integrin-binding sites located in the last domain of CCN1 [10], only $\alpha_{v} \beta_{3}$ integrin matched. To determine the type of integrin responsible for the induction of $C C N 1$ pre-mRNA splicing, INA-6 cells were incubated with $\alpha_{v} \beta_{3}$ blocking antibody and CCN1-Fc, which showed no reduction in splicing (data not shown). We further performed blocking experiments with anti-integrin $\beta_{1}, \beta_{2}, \beta_{3}, \beta_{7}$ antibodies, as these integrins are described as being expressed on myeloma cells [43], and integrins $\alpha_{6} \beta_{1}$ and $\alpha_{M} \beta_{2}$, which interact with the CT-domain of CCN1 [10]. No anti-integrin antibody was able to block splicing mediated by stimulation with CCN1-Fc (data not shown).

\section{CCN1-Fc enhances INA- 6 cell viability in the absence of IL-6}

It has previously been shown that survival of both INA-6 cells and primary myeloma cells is independent of IL-6 when cultured with MSC [38]. We next wanted to investigate whether $\mathrm{CCN} 1$, as a MSC-derived factor, has a positive effect on myeloma cell viability. Therefore, pre-starved INA-6 cells were incubated with varying concentrations of CCN1-Fc for $24 \mathrm{~h}$, in the absence of IL-6, and cell viability was assessed through quantification of ATP content. Cell viability was increased by $\sim 40 \%$ when treated with $0.05 \mu \mathrm{g} /$ $\mathrm{ml}$ or $2.5 \mu \mathrm{g} / \mathrm{ml} \mathrm{CCN1-Fc} \mathrm{and} \mathrm{further} \mathrm{significantly} \mathrm{en-}$ hanced to $50 \%$ when cells were incubated with $0.1 \mu \mathrm{g} / \mathrm{ml}$ or $1 \mu \mathrm{g} / \mathrm{ml}$ CCN1-Fc compared to control cells treated with Fc-Tag (Figure 4A). Enhanced cell viability was not accompanied with reduced apoptosis induction or enhanced phosphorylation of STAT3, Erk1/2 or p38 MAPK (data not shown). Additionally, in the presence of IL-6, incubation with $0.05 \mu \mathrm{g} / \mathrm{ml}-2.5 \mu \mathrm{g} / \mathrm{ml}$ CCN1-Fc showed only a marginal $15 \%$ increase in cell viability while treatment with 5 $\mu \mathrm{g} / \mathrm{ml}$ CCN1-Fc had no effect (Figure 4B).

\section{Discussion}

In the present study, we expand knowledge on regulatory mechanisms involving splicing of the proangiogenic, matricellular growth and differentiation factor CCN1/CYR61 in the tumor microenvironment with a special focus on myeloma-MSC interaction. Our new findings include mechanistic data on the role of intron retention and splicing as a means of translation regulation of immediate early proteins of the $\mathrm{CCN}$ family as well as putative biological functions of CCN1 as a factor promoting myeloma cell viability.

CCN1, according to genetic mouse models and in vitro signaling experiments, is involved in angiogenesis and
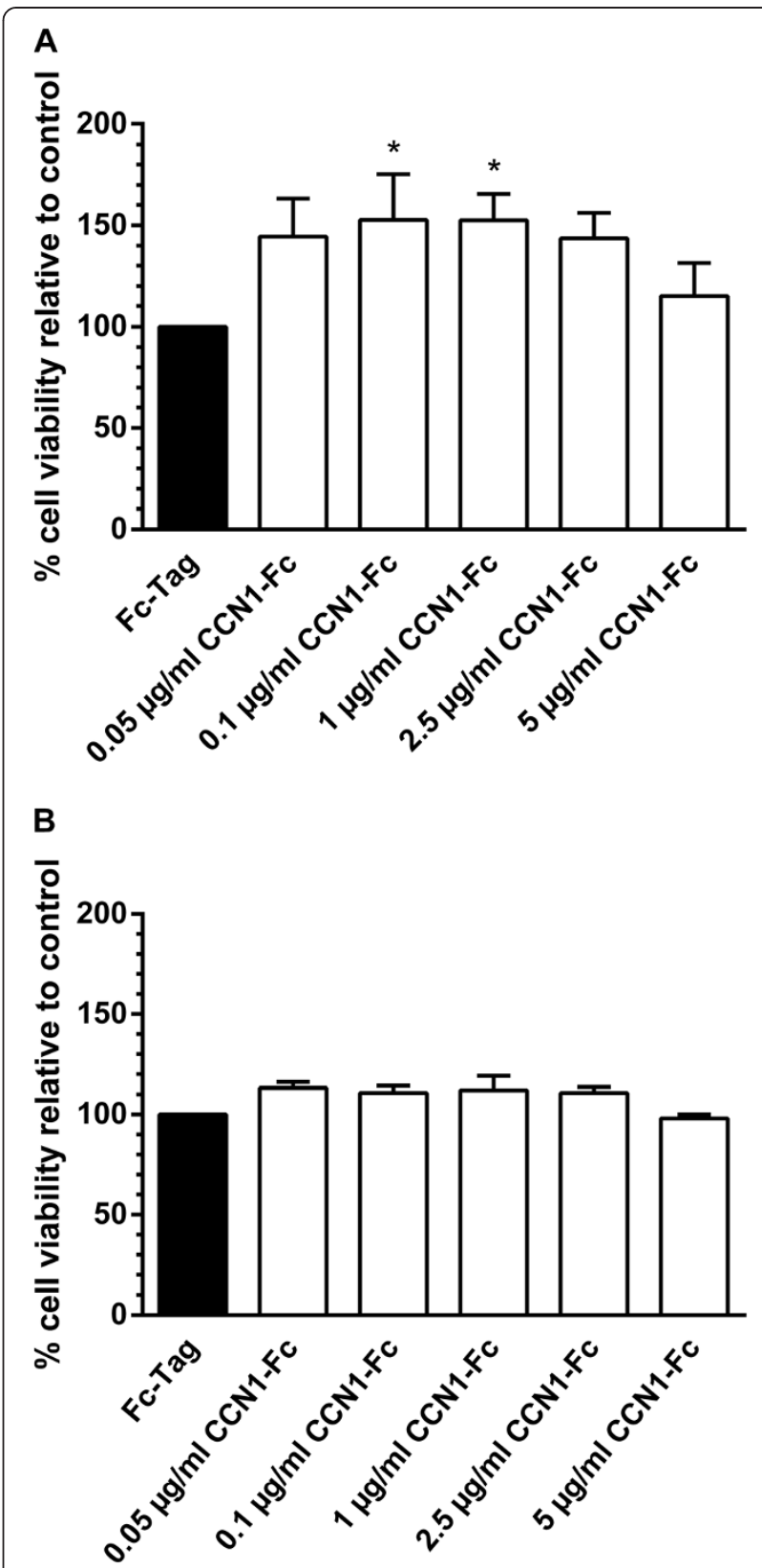

Figure 4 CCN1-Fc enhances INA-6 cell viability in the absence of IL-6. INA-6 cells were cultured with serum-reduced media for 24 $\mathrm{h}$ before stimulation with (A) CCN1-FC or (B) CCN1-FC and IL-6. After $24 \mathrm{~h}$, cell viability was measured by quantification of ATP. In the absence of IL-6, INA- 6 cell viability was significantly enhanced when

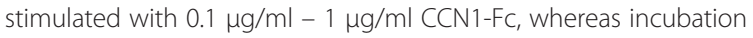
with $0.05 \mu \mathrm{g} / \mathrm{ml}-2.5 \mu \mathrm{g} / \mathrm{ml}$ CCN1-Fc led to a slight enhancement of INA-6 cell viability in presence of IL-6. Results depicted graphically represent the mean + SD for four independent experiments. ${ }^{*} p<0.05$ relative to control.

anoikis $[4,6,14,44,45]$. It is expressed in regenerating/ proliferating MSC and osteoblast precursors but not in mature bone cells $[7,8]$. Earlier and recent reports have demonstrated that CCN1 is expressed in MM myeloid and 
lymphoid cells, as well as other tumor cells such as breast and prostate cancer, and may contribute to tumor cell survival by providing signals stimulating angiogenesis and survival through acquire anoikis resistance [14,44,46-48]. We observed CCN1 intron splicing in INA-6 myeloma cells for all four introns of the CCN1 mRNA and enhanced transcription of CCN1 after co-culture with MSC. This extends previous findings of intron splicing with regard only to intron 3 in CCN1 mRNA of breast cancer cells [18]. The presence of 2 pre-mature stop codons within this intron 3retaining mRNA sequence suggested the possible existence of truncated CCN1 proteins containing domain 1 and 2 . However, our finding of intron 1-4 retention in myeloma cells, and the presence of an in-frame stop codon downstream to the CCN1 signal sequence (within intron 1) implies that intron 1-4 retaining CCN1 mRNA completely blocks endogenous translation of full length $\mathrm{CCN} 1$ protein in INA-6 cells, preventing translation of truncated variants that could be termed isoforms resulting from alternative splicing [15]. Moreover induction of splicing through contact with MSC is initiated at all introns and allows for full length protein expression in INA-6 cells, as confirmed by the increase in $\mathrm{CCN} 1$ protein using an antibody directed towards the hinge region. As this part of the protein offers the most diversity to the other members of the $\mathrm{CCN}$ family [11], antibodies directed against the variable linker region will cause less cross-reactivity to other $\mathrm{CCN}$ proteins and higher specificity than domain-specific antibodies.

In the case of breast cancer, alternative splicing of intron 3 in CCN1 pre-mRNA is regulated by hypoxia and acidosis which further leads to disease progression $[17,18]$. In the case of MM, changes in CCN1 mRNA splicing patterns appear independent of $\mathrm{pH}$ change and oxygen deficiency, nor is it mediated by soluble factors, as indirect co-culture with MSC using trans-well inserts, as well as by incubating with MSC-derived conditioned media, was not sufficient to induce CCN1 splicing in INA-6 cells. However, recombinant human Fc-tagged CCN1 protein was capable of inducing this phenomenon. We therefore hypothesized that the native $\mathrm{CCN} 1$ protein is rapidly aggregating on cell surfaces and materials of cell culture flasks, and thus, is not available (in sufficient quantity) in the soluble phase. This hypothesis is further confirmed by previous findings that CCN1, although it contains an N-terminal secretory signal peptide, is not secreted into the supernatant and instead, remains associated with the extracellular matrix, leading to restriction of CCN1 action to the local microenvironment [49]. In contrast the recombinant CCN1-Fc protein shows greater stability in solution and induces CCN1 mRNA splicing when added to cell cultures. As the amount of intron-free isoform of CCN1 mRNA increased compared to total CCN1 mRNA, and because increases in the intron-free isoform is accompanied with a decrease in the intron-retained isoform, we suspect that splicing induction is an important regulatory mechanism. In addition, densitometric analyses and qPCR revealed that incubation with CCN1-Fc further led to enhanced transcription of CCN1 mRNA, and that this enhancement is a rapid process which responds in a dose-dependent manner. As well as being a rapid process, concentrations as low as $0.05 \mu \mathrm{g} / \mathrm{ml} \mathrm{CCN1-Fc} \mathrm{was} \mathrm{suffi-}$ cient to induce splicing, suggesting a highly sensitive response to CCN1 levels. Additionally, once primed with CCN1-Fc, splicing patterns were detectable up to three days after stimulation, suggesting a long-lasting signature. We conclude that $\mathrm{CCN} 1$ protein, delivered in a paracrine manner, is an appropriate stimulus to initiate complete splicing of intron-retaining CCN1 mRNA in myeloma cells, which further leads to protein translation in the target cell, maintaining further CCN1 expression in an autocrine manner. The fact that CCN1 production in histological sections of MM patients is located in cells that are not directly located adjacent to bone-derived cells favors a long term signature in $\mathrm{MM}$ cells, which remains after contact with CCN1-producing bone cells, though other stimulators cannot be excluded. Production of CCN1 by myeloma cells in addition to CCN1 derived from cells in the bone marrow may further lead to an angiogenic switch that is associated with disease progression [50].

CCN proteins are involved in many different cellular functions depending on their interacting partners mainly integrins - expressed on the cell surface. The CT domain, as well as the TSR and $\mathrm{vWC}$ domain, include several integrin-binding sites that promote the activity of $\mathrm{CCN}$ proteins $[5,11,51]$. The CT domain contains several integrin-binding sites for $\alpha_{6} \beta_{1}, \alpha_{M} \beta_{2}$, and $\alpha_{v} \beta_{3}$ integrins, whereas the integrin $\alpha_{6} \beta_{1}$ can bind the TSR domain and integrin-binding sites for $\alpha_{v} \beta_{3}, \alpha_{v} \beta_{5}$, and $\alpha_{I I b} \beta_{3}$ are located within the vWC domain $[10,51]$. Several integrins, such as $\alpha_{v} \beta_{3}$ and $\alpha_{v} \beta_{5}$, bind their ligands by recognizing RGD sequences [42]. To elucidate the mechanism involved in splicing, we incubated INA- 6 cells with full length and truncated $\mathrm{CCN} 1$ proteins that contain domain 1-3, 1-2, or domain 1 only. Polypeptides lacking domain 4 did not show any effect, suggesting that domain 4, also known as the CT domain, is necessary for splicing induction. Furthermore, blocking RGD-dependent integrins on INA- 6 cells by pre-incubation with GRGDSP peptide abolished CCN1-induced splicing in INA-6 cells, supporting the hypothesis of an integrin-mediated mechanism. CCN1 does not contain an RGD sequence motif, but RGD-blocking peptides have been previously reported to also abolish other effects of $\mathrm{CCN}$ proteins [41]. Blocking antibodies targeting $\beta$-integrins $\left(\beta_{1}, \beta_{2}, \beta_{3}\right.$, and $\left.\beta_{7}\right)$ that are relevant in myeloma [43], as well as $\alpha_{v} \beta_{3}$, the RGD-sensitive integrin comprised in CT domain, were unable to prevent the splicing induction of CCN1 mRNA by CCN1-Fc stimulation. We can only speculate on the reason for this discrepancy, one of which may be that 
binding sites involved are not targeted by hitherto available antibodies. Thus, we suggest that splicing induction may be a complex mechanism, dependent on engagement of several integrins and/or co-receptors that require further investigations.

In general, multiple myeloma cells, if removed from the bone marrow, often cannot survive without feeder cells or supplementation of factors to cell cultures, e.g. IL-6 in case of the INA-6 cell line [52]. In the case of co-culture with MSC, myeloma cells survive independent of the IL-6/gp130/STAT3 pathway [38] suggesting that other pro-myeloma factors, such as $\mathrm{CCN} 1$, are provided by the stromal tumor microenvironment. We were able to detect a significantly increased cell viability of myeloma cells after CCN1 incubation independent of IL-6 suggesting CCN1 as a microenvironment-derived pro-myeloma factor. CCN1-dependent signaling pathways were not involved mechanistically in this promyeloma effect as no alterations in phosphorylated p38, ERK1/2, and STAT3 by CCN1 treatment of INA- 6 cells was observed.

\section{Conclusions}

Taken together, we show that INA-6 myeloma cells are able to produce functional $\mathrm{CCN} 1$ protein after MSC contact, which is induced by a splicing event concerning all introns as well as enhanced transcription. MSC-dependent splicing that governs $\mathrm{CCN} 1$ protein translation, as shown here, is extremely relevant in both physiologic processes like regeneration and in tumor development, e.g. by enhancing angiogenesis, especially in myeloma bone disease. MSC have been reported to support or to suppress tumorigenesis and this is certainly one of the more protective effects [53]. MSC-based treatment strategies in MM must be critically examined with regard to the oncogenic splicing switch potential of $\mathrm{CCN} 1$. In order to survive within the bone marrow, MM cells produce a series of modulatory factors for osteogenic differentiation to suppress e.g. osteoblastderived inhibitory factors for MM growth and survival $[26,32,54,55]$. In addition, MM cells, by either physical contact or humoral factors, stimulate stromal osteogenic precursors to produce supportive factors, e.g. IL-6. Such contact-mediated signatures of the transcriptome in stromal osteogenic precursors may also persist as a permissive situation in myeloma cells. Our findings suggest CCN1 as a MSC-induced factor with relevance in tumor relapse and development of secondary malignancies.

\section{Methods}

\section{Ethics statement}

Bone material was used according to the permission of the local Ethics Committee (Medical Faculty of the University of Wuerzburg) and after having obtained written, informed consent of each patient.

\section{Reagents and antibodies}

Primary antibodies for western blot analyses were directed against: CCN1 (CYR61 H-78, rabbit, sc-13100; Santa Cruz Biotechnology, Heidelberg, Germany), Tyr705-phosphorylated STAT3 (rabbit mAb, \#9145; New England Biolabs (NEB), Beverly, MA, USA), Thr202/Tyr204 phosphorylated p44/42 MAPK (ERK1/ 2) (rabbit, \#9101; NEB), and Thr180/Tyr182 p38 MAPK (rabbit mAb, \#9215; NEB). Loading control antibodies were specific for: $\beta$-actin (rabbit mAb, \#4970; NEB), STAT3 (rabbit, \#4904; NEB), p42/44 MAPK (mouse $\mathrm{mAb}$, \#4696; NEB), and p38 $\alpha$ MAPK (mouse mAb, \#9217; NEB). Anti-rabbit antibody (goat-anti-rabbit IgG (whole molecule)-peroxidase, A0545; Sigma Aldrich Chemie (Sigma), Schnelldorf, Germany) and anti-mouse antibody (goat-anti-mouse IgG (Fab specific)-peroxidase, A9917; Sigma) were used as secondary antibodies. To block RGD-dependent integrins, blocking peptide (Gly-Arg-Gly-Asp-Ser-Pro, GRGDSP, SCP0157) and control peptide (Gly-Arg-Ala-Asp-Ser-Pro, GRADSP, SCP0156) were purchased from Sigma. The following functional-blocking antibodies against several integrins were obtained: $\beta 1$ (monoclonal mouse IgG1, MAB 17781; R \& D Systems (R \& D), Wiesbaden, Germany), $\beta 2$ (antigen affinity purified polyclonal goat IgG, AF 1730 ; R \& D), $\beta 3$ (monoclonal mouse IgG1, NBP128398; Novus Biologicals, Littleton, CO, USA), $\beta 7$ (monoclonal rat IgG2a, K, 321218; BioLegend, San Diego, CA, USA), $\alpha_{v} \beta_{3}$ (monoclonal mouse IgG1, MAB 3050; R \& D). Isotype antibodies were used as control: Rat IgG2a, א (400516; BioLegend), mouse IgG1 (MAB002; R \& D), normal goat IgG (sc-2028; Santa Cruz).

\section{Cell culture}

Primary MSC of healthy donors were isolated from bone marrow of femoral heads after total hip arthroplasty and characterized as previously described $[8,56]$. MSC were selected by surface adherence and expanded in DMEM/ Ham's F-12 (1:1) (PAA Laboratories (PAA), Linz, Austria) supplemented with 10\% (vol/vol) FCS (Biochrom, Berlin, Germany), $1 \mathrm{U} / \mathrm{ml}$ penicillin, $100 \mu \mathrm{g} / \mathrm{ml}$ streptomycin (PAA) and $50 \mu \mathrm{g} / \mathrm{ml} \mathrm{L-ascorbic} \mathrm{acid} \mathrm{2-}$ phosphate (Sigma). All experiments were performed with MSC in passage 1. Osteogenic precursor cells $(\mathrm{OPC})$ were generated by incubating MSC with osteogenic differentiation media for 14 days. Osteogenic differentiation media consisting of DMEM High Glucose media (PAA) with $10 \%$ (vol/vol) FCS, $1 \mathrm{U} / \mathrm{ml}$ penicillin, $100 \mu \mathrm{g} / \mathrm{ml}$ streptomycin and additionally supplemented with $10 \mathrm{mM} \beta$-glycerophosphate disodium salt hydrate (Sigma), $100 \mathrm{nM}$ dexamethasone (Sigma) and $50 \mu \mathrm{g} / \mathrm{ml}$ L-Ascorbic acid-2-phosphate sesquimagnesium salt hydrate (Sigma). Osteogenic differentiation was checked 
with histological staining for alkaline phosphatase using the Alkaline Phosphatase, Leukocyte Kit 86-C (Sigma) and mineralized extracellular matrix was visualized by staining with alizarin red S (Sigma). The cell line INA-6 [52] was maintained in RPMI 1640 complete medium that is generated by adding 20\% (vol/vol) FCS, $100 \mu \mathrm{g} /$ $\mathrm{ml}$ gentamycine, $2 \mathrm{mmol} / \mathrm{l}$ glutamine (PAA), $1 \mathrm{mmol} / \mathrm{l}$ Na-pyruvate (Sigma) to RPMI 1640 media (PAA, Linz, Austria). INA- 6 cells were cultivated with a final concentration of $2 \mathrm{ng} / \mathrm{ml}$ recombinant human interleukin-6 (IL-6; R \& D). For measuring cell viability and apoptosis, INA- 6 cells were pre-starved by incubating with serum reduced RPMI 1640 complete medium containing 4\% (vol/vol) FCS and $2 \mathrm{ng} / \mathrm{ml} \mathrm{IL-6}$ for $24 \mathrm{~h}$. Starvation media permits cultivation of INA- 6 cells over $48 \mathrm{~h}$ without inducing enhanced cell death compared to control (proved by trypan blue exclusion). All cell cultures were regularly tested for mycoplasma and grown at $37^{\circ} \mathrm{C}$ and $5 \% \mathrm{CO}_{2}$. For experiments under hypoxic conditions, cultures were incubated in an incubator adjusted to $1 \% \mathrm{O}_{2}$. In parallel, control cells were cultured under normoxia $\left(21 \% \mathrm{O}_{2}\right)$. Acidic conditions were generated by culturing INA-6 cells in consumed media.

\section{Direct and indirect co-cultures of MM cells with MSC}

$5 \times 10^{5}$ MSC were seeded per well (6-well plate) and given time to attach for one day. $2 \times 10^{6}$ INA- 6 cells, washed once with PBS, were either added to the MSC or cultured with 2 ng/ml IL-6 (control) in a mixture of DMEM/Ham's F12 and RPMI 1640 (1:1). After $24 \mathrm{~h}$ of co-culture, INA-6 cells were carefully rinsed off the MSC layer with PBS. To prevent contamination of INA-6 cells with MSC, rinsing was performed with regard to leaving the MSC layer intact as well as by staining INA-6 cells with CellTracker ${ }^{\text {Tn }}$ Green 5chloromethylfluorescein diacetate (CMFDA, $5 \mu \mathrm{M}$; PA3011, Lonza Group, Basel, Switzerland) according to the manufacturer's instructions before performing co-culture. Detached INA- 6 cells were examined afterwards by using a fluorescence microscope (Microscope Axiovert 25; Zeiss, Jena, Germany). As no unstained cells were detected, contamination with MSC was excluded. In the case of indirect co-culture using trans-well inserts, MSC were seeded as previously described on 6-well tissue culture polystyrene plates (Corning, NY, USA) and INA-6 cells were transferred on polyester membrane insert $(0.4 \mu \mathrm{m}$ pore size).

Preparation of MSC-derived conditioned media (MSC-CM) MSC-CM was generated from MSC supernatant after 48-72 h of culture after passing through a $0.2 \mu \mathrm{m}$ filter to eliminate remained cellular debris and contaminating cells. In parallel, $2 \times 10^{6}$ INA- 6 cells were centrifuged at $1200 \mathrm{rpm}$ and cell pellet was resuspended in $5 \mathrm{ml} \mathrm{MSC}$ $\mathrm{CM}$ or, in the case of control, in $5 \mathrm{ml} \mathrm{MSC}$ media, supplemented with $2 \mathrm{ng} / \mathrm{ml}$ IL-6 and incubated for $24 \mathrm{~h}$. The next day, cells were harvested for RNA isolation.

\section{Protein extraction and western blot analyses}

For CCN1 detection, INA-6 control cells were cultured with $2 \mathrm{ng} / \mathrm{ml}$ IL-6 or co-cultured with MSC and harvested as described above. To investigate signaling pathways, INA-6 cells were incubated with IL-6-deprived media for $20 \mathrm{~h}$, washed, and stimulated with CCN1-Fc or Fc-Tag for $30 \mathrm{~min}$ or $60 \mathrm{~min}$ after starving for $4 \mathrm{~h}$ in serum-free media.

To generate whole cell lysates, cells were washed with PBS and incubated with lysis buffer (\#9803; NEB) supplemented with complete, EDTA-free protease inhibitor cocktail (\#04693132001; Roche, Mannheim, Germany) and PhosStop phosphatase inhibitor cocktail (\#0496845001; Roche) for $10 \mathrm{~min}$ on ice. After sonication with an ultrasonic homogenizer (Sonopuls, Bandelin), cell lysates were cleared by centrifugation (12000 rpm, $15 \mathrm{~min}, 4^{\circ} \mathrm{C}$ ). Protein concentrations were determined using the Bradford assay (Roti-Quant; Carl Roth, Karlsruhe, Germany). Equal amounts of proteins mixed with Laemmli buffer were heated up to $95^{\circ} \mathrm{C}$ for $5 \mathrm{~min}$ and run on sodium dodecyl sulphate $10 \%$-polyacrylamide gels before blotting on polyvinyldifluoride (PVDF) membranes (WESTRAN ${ }^{\circledR}$ clear signal; GE Healthcare Europe GmbH, Freiburg, Germany). Blots were incubated in blocking buffer (p38 $\alpha$ MAPKp44/42 MAPK (Erk1/2), After four washes with buffer, the blots were incubated with corresponding peroxidase-conjugated secondary antibody in corresponding blocking buffer for 2 $\mathrm{h}$ at room temperature. Visualization of the blots was performed with the enhanced chemiluminescence (ECL) system (Amersham ECL Prime Western Blotting Detection Kit; GE Healthcare Europe GmbH, Freiburg, Germany) and X-ray films (Fuji Medical X-ray film Super RX, Fujifilm Europe $\mathrm{GmbH}$, Düsseldorf, Germany). Loading was determined by stripping the membrane and re-blotting with corresponding control antibody.

\section{RNA isolation and polymerase chain reaction (PCR)}

Total RNA was isolated from INA-6 cells using the NucleoSpin ${ }^{\bullet}$ RNA II kit (Machery-Nagel GmbH \& Co. KG, Düren, Germany) according to the manufacturer's instructions. Purity and yield of the RNA were photometrically determined. cDNA was synthesized by using 1 $\mu \mathrm{g}$ of total RNA, random primers (Life Technologies GmbH, Darmstadt, Germany), and M-MLV reverse transcriptase (Promega GmbH (Promega), Mannheim, Germany) according to the manufacturer's instructions.

Semi-quantitative PCR analyses were carried out in a volume of $30 \mu$ l containing $6 \mu \mathrm{l} 5 \times$ Green GoTaq ${ }^{\oplus}$ Flexi Buffer (\#M891A, Promega), 20 ng cDNA, $1.7 \mathrm{mM} \mathrm{MgCl}_{2}$ (\#A351H; Promega), 0.3 mM dNTPs (Bioline, Luckenwalde, Germany), 1 unit GoTaq ${ }^{\circledR}$ DNA Polymerase (Promega) and 
5 pmol sequence specific primers (Eurofins MWG Operon, Ebersberg, Germany) for $\mathrm{CCN} 1$ gene or the housekeeping gene eukaryotic translation elongation factor 1 alpha 1 (EEF1A1). Intron-spanning primer sequences for CCN1 (accession number DNA sequence: NC_000001.10) were obtained by using the online software Primer3Plus (see Table 1 for primer sequences). PCR was run in a peqSTAR $2 \times$ thermocycler (Peqlab Biotechnologie $\mathrm{GmbH}$, Erlangen, Germany) as follows: $2 \mathrm{~min}$ at $95^{\circ} \mathrm{C}, 95^{\circ} \mathrm{C}$ for $30 \mathrm{sec}, 50-56^{\circ}$ $\mathrm{C}$ for $30 \mathrm{sec}$ (EEF1A1 and intron-4 spanning CCN1 primer (CCN1 4-5)) or $45 \mathrm{sec}$, and $72^{\circ} \mathrm{C}$ for 1 min (37-43 cycles for $C C N 1,22-25$ cycles for $E E F 1 A 1$ ), finished by $72^{\circ} \mathrm{C}$ for 3 min. For long-range PCR primer pairs CCN1 1-2 forward and CCN1 4-5 reverse were used. Annealing temperature was adjusted to $52^{\circ} \mathrm{C}$, elongation time to $2 \mathrm{~min}$. Separation of $10 \mu \mathrm{l}$ of PCR products occurred on a $2 \%$ agarose gel containing GelRed (\#M3199; Genaxxon Bioscience GmbH, Ulm, Germany). Specificity of PCR products was verified by sequence analyses using Big Dye Terminator v1.1 Cycle Sequencing Kit and ABI 3130xL Genetic Analyzer (Applied Biosystems, Darmstadt, Germany).

Quantitative real-time PCR (qPCR) was performed in a volume of $20 \mu \mathrm{l}$ with $1 \mu \mathrm{l}$ of cDNA, which was previously diluted 1:5, $10 \mu \mathrm{l}$ KAPA SYBR FAST Universal qPCR Master Mix (Peqlab Biotechnologie GmbH, Erlangen, Germany) and 1 pmol each forward and reverse primers (biomers.net GmbH, Ulm, Germany) by using Opticon DNA Engine (MJ Research, Watham, USA). Amplification of CCN1 gene was performed by using primers specific for exons 4-5 (5'-primer, $5^{\prime}$-ACGAGT TACCAATGACAACC-3'; 3'-primer, 5'-CCAGCGTAA GTAAACCTGAC-3'). As an internal control, mRNA expression level of housekeeping gene RPS27A was amplified with following sequence specific primers ( $5^{\prime}$-primer; 5'-TCGTGGTGGTGCTAAGAAAA-3'; 3'-primer, 5' TCTCGACGAAGGCGACTAAT-3'). QPCR conditions were as follows: $95^{\circ} \mathrm{C}, 3 \mathrm{~min} ; 40$ cycles: $95^{\circ} \mathrm{C}, 15 \mathrm{~s} ; 60^{\circ} \mathrm{C}$ for RPS27A, $57^{\circ} \mathrm{C}$ for $C C N 1,15 \mathrm{~s} ; 72^{\circ} \mathrm{C}, 20 \mathrm{~s}$; followed by melting curve analysis for specificity of qPCR products. qPCRs were performed three times, results were calculated with the $\Delta \Delta \mathrm{ct}$ method and significances with the Relative Expression Software Tool (REST 2009 V2.0.13) obtained from Qiagen GmbH (Hilden, Germany) [39].

\section{Expression and purification of recombinant CCN1 protein (CCN1-FC) and CCN1 domains (CCN1-Fc 1-3, CCN1-Fc 1-2, CCN1-Fc 1)}

The cloning of CCN1, as well as the preparation of the virus stock of CCN1-Fc, was generated as previously described [57]. Additionally, to express recombinant CCN1-Fc proteins lacking domain 4 (CCN1-Fc 1-3), domains 3 and 4 (CCN1-Fc 1-2) or domains 2-4 (CCN1-Fc $1)$, respectively, corresponding open reading frames were similarly cloned and expressed. To purify the CCN1-Fc protein, as well as the domain-lacking proteins or Fc-Tag protein, $1 \mathrm{ml}$ HiTrap Protein G HP columns were used with a peristaltic pump P-1 (GE Healthcare Europe $\mathrm{GmbH}$, Freiburg, Germany). $75 \mathrm{ml}$ cell supernatant was filtered $(0.2 \mu \mathrm{m})$ and transferred to a PBS equilibrated column. Columns were washed with PBS for $15 \mathrm{~min}$ before protein was eluted with elution buffer $(0.1 \mathrm{M}$ glycine, $\mathrm{pH} 2.2$ ). Previously provided $3 \mathrm{M}$ Tris $/ \mathrm{HCl}, \mathrm{pH} 8$ immediately neutralized eluted protein fractions. Protein was further used for gel electrophoresis and purity was checked by silver staining and western blotting using FcTag antibody, as previously described [57]. Proteins were stored at $-20^{\circ} \mathrm{C}$ until use. After thawing, the tube was centrifuged and after transferring the supernatant into a fresh tube, protein concentration was determined by Bradford assay.

\section{Treatment of INA-6 cells with CYR61-Fc and truncated CYR61-Fc proteins}

INA- 6 cells were seeded in 24 well-plates $\left(3 \times 10^{5}\right.$ cells/well $)$ and treated with CCN1-Fc, truncated CCN1-Fc isoforms, or Fc-Tag for control. The quantity of truncated proteins or Fc-Tag was added in equimolar concentration compared to the full-length protein CCN1-Fc. At indicated time points, cells were harvested for RNA isolation.

For blocking integrin signaling, INA-6 cells were seeded as mentioned above and pre-incubated for 45 min with $55 \mu \mathrm{g} / \mathrm{ml}$ GRGDSP peptide (control: GRADSP peptide) or $22 \mu \mathrm{g} / \mathrm{ml}$ anti-integrin antibody (control: isotype antibody) at $37^{\circ} \mathrm{C}$ and $5 \% \mathrm{CO}_{2}$. For $24 \mathrm{~h}$ incubation, CCN1-Fc or Fc-Tag was added as previously described at a final concentration of $50 \mu \mathrm{g} / \mathrm{ml}$ peptide or $20 \mu \mathrm{g} / \mathrm{ml}$ anti-integrin antibody.

\section{Cell viability assays}

Pre-starved INA- 6 cells were washed once with PBS, resuspended in starvation media with or without IL-6 and seeded in a 96-well plate (1250 cells/well). To assess the influence of CCN1-Fc on cell viability, INA- 6 cells were stimulated in triplicate for $24 \mathrm{~h}$ with CCN1-Fc at a final concentration ranging from $0.1 \mu \mathrm{g} / \mathrm{ml}$ to $5 \mu \mathrm{g} / \mathrm{ml}$, or with Fc-Tag $(1.9 \mu \mathrm{g} / \mathrm{ml}$; adapted to the highest CCN1-Fc concentration) for control. Proliferation was quantified by CellTiter-Glo ${ }^{\circ}$ Luminescent Cell Viability Assay and apoptosis was determined by CaspaseGlo ${ }^{\circ}$ 3/7 Assay (both Promega) according to the manufacturer's instructions and by measuring luminescence with an Orion II luminometer (Berthold Detection Systems, Pforzheim, Germany).

\section{Statistical analysis}

Results were expressed as mean $+\mathrm{SD}$ from four independent experiments. Influence of CCN1-Fc on cell 
viability was calculated by nonparametric Kruskal-Wallis analysis with Dunn's post-hoc multiple comparison test using GraphPad Prism 6.03 (GraphPad Software, CA, USA). $P$ values less than 0.05 were considered to be statistically significant. Significances of qPCR analysis was calculated with the Relative Expression Software Tool (REST 2009 V2.0.13) obtained from Qiagen $\mathrm{GmbH}$ (Hilden, Germany) [39].

\section{Additional files}

Additional file 1: Figure S1. Nucleotide sequence of CCN1 gene. CCN1 sequence (accession number DNA sequence: NC_000001.10) including coding sequence (CDS) (underlined), parts of exon 1 and 2 (capital letters), intron 1 (gray, lower case letters) and stop codon (box). Arrows represent location of CCN1 1-2 primers.

Additional file 2: Figure S2. Splicing of CCN1 is not induced in INA-6 cells by MSC-derived conditioned media (MSC-CM). INA- 6 cells were cultured either alone (-) or with CM of three different MSC donors (+). After $24 \mathrm{~h}$ of incubation, INA-6 cells were harvested and splicing pattern of CCN1 pre-mRNA was investigated by semi-quantitative PCR and intron-4 spanning primers. Both, control cells (-) and cells incubated with $\mathrm{CM}(+)$ expressed the intron-retaining RNA isoform. Housekeeping gene EEFTA1 served as control.

Additional file 3: Figure S3. Splicing of $\mathrm{CCN} 1$ is a rapid, concentrationdependent event in INA-6 cells. INA-6 cells were incubated with varying concentrations of CCN1-Fc for $4 \mathrm{~h}, 8 \mathrm{~h}$, or $24 \mathrm{~h}$. (A) Afterwards, splicing of CCN1 was determined by semi-quantitative PCR and by using primers for exons 4-5 (CCN1 4-5), whereas EEFTA7 served as control. (B) Bar graphs display the relative expression of intron-free isoform, which increases with concentration but not with duration of incubation.

Additional file 4: Figure S4. Incubation with CCN1-FC promotes CCN1 transcription in INA-6 cells. (A-B) INA-6 cells were incubated with Fc-Tag (control) or varying concentrations of CCN1-Fc for $24 \mathrm{~h}$. After total RNA isolation, (A) semi-quantitative PCR, using primers for exons 4-5 (CCN1 $4-5$ ), and (B) qPCR analyses, using intron 4 spanning primers, were performed for CCN1 mRNA expression. Data were normalized relative to mRNA expression levels of housekeeping gene (A) EEF1A1 or (B) RPS27A. Results were normalized to Fc-Tag-incubated control cells, which were defined as 1. Results shown in (B) represent mean + SD of triplicate measurement.

\section{Abbreviations}

BMP: Bone morphogenetic proteins; CCN1: CCN family member 1; CCN2: CCN family member 2; CCN3: CCN family member 3; CDS: Coding sequence; CM: Conditioned media; CT: Carboxy-terminal domain; CTGF: Connective tissue growth factor; CYR61: Cysteine rich angiogenic inducer 61; DKK-1: Dickkopf-1; ECM: Extracellular matrix; EEF1A1: Eukaryotic translation elongation factor 1 alpha 1; EMT: Epithelial mesenchymal transition; ERK: Extracellular signal-regulated kinase; FCS: Fetal calf serum; IGFBP: Insulin-like growth factor binding protein; IL-6: Interleukin-6; MAPK: Mitogen-activated protein kinase; MM: Multiple myeloma; MSC: Mesenchymal stem cells; NOV: Nephroblastoma overexpressed; OPC: Osteogenic precursor cells; PBS: Phosphate buffered saline; PCR: Polymerase chain reaction; PTH1R: Parathyroid hormone 1 receptor; PVDF: Polyvinyldifluoride; RANKL: Receptor activator of NFKB ligand; RPS27A: Ribosomal protein S27a; SD: Standard deviation; SFRP2/3: Secreted frizzled related proteins 2 and 3; STAT3: Signal transducer and activator of transcription 3; SOST: Sclerostin; TBS: Tris buffered saline; TGF $\beta$ : Transforming growth factor-beta; TNFa: Tumor-necrosis factor alpha; TSR: Thrombospondin type I repeat (TSR); VWC: von Willebrand factor type C.

\section{Competing interest}

The authors declare that they have no competing interests.

\section{Authors' contributions}

$J D$ : carried out the experiments and wrote the manuscript; RE, SK and RJT: drafted the manuscript; FJ and NS: conceived the study, participated in the design of the study and drafted the manuscript. All authors read and approved the final manuscript.

\section{Author's information}

Senior authorship Franz Jakob and Norbert Schütze.

\section{Acknowledgement}

This work was funded by The German Research Foundation within the Clinical Research Group-1586 SKELMET and the University of Wuerzburg in the funding programme Open Access Publishing. We thank Dr. Kurt Bommert for providing the INA-6 cell line, the orthopedic surgeons who supplied us with human femoral heads, Beate Geyer, Jutta Schneidereit, Jutta Meissner-Weigl, Sabine Zeck, and Susanne Wiesner for technical assistance, Viola Zehe for the preparation of MSC, and Dr. Alexander Keller for statistical assistance.

\section{Author details}

'Orthopedic Center for Musculoskeletal Research, Orthopedic Department, University of Würzburg, Brettreichstrasse 11, 97074 Würzburg, Germany. ${ }^{2}$ Department of Internal Medicine II, University Hospital of Würzburg, Josef-Schneider Str. 2, 97080 Würzburg, Germany. ${ }^{3}$ Section Biomedical Imaging, Department of Diagnostic Radiology, University Hospital Schleswig-Holstein, Campus Kiel, Germany.

Received: 11 February 2014 Accepted: 6 June 2014 Published: 25 June 2014

\section{References}

1. Leask A, Abraham DJ: All in the CCN family: essential matricellular signaling modulators emerge from the bunker. J Cell Sci 2006 , 119:4803-4810.

2. Chaqour B, Goppelt-Struebe M: Mechanical regulation of the Cyr61/CCN1 and CTGF/CCN2 proteins. FEBS / 2006, 273:3639-3649.

3. Rachfal AW, Brigstock DR: Structural and functional properties of CCN proteins. Vitam Horm 2005, 70:69-103.

4. Schutze N, Lechner A, Groll C, Siggelkow H, Hufner M, Kohrle J, Jakob F: The human analog of murine cystein rich protein 61 [correction of 16] is a 1alpha,25-dihydroxyvitamin D3 responsive immediate early gene in human fetal osteoblasts: regulation by cytokines, growth factors, and serum. Endocrinology 1998, 139:1761-1770.

5. Chen CC, Lau LF: Functions and mechanisms of action of CCN matricellular proteins. Int J Biochem Cell Biol 2009, 41:771-783.

6. Mo FE, Muntean AG, Chen CC, Stolz DB, Watkins SC, Lau LF: CYR61 (CCN1) is essential for placental development and vascular integrity. Mol Cell Biol 2002, 22:8709-8720.

7. Lienau J, Schell H, Epari DR, Schutze N, Jakob F, Duda GN, Bail HJ: CYR61 (CCN1) protein expression during fracture healing in an ovine tibial model and its relation to the mechanical fixation stability. J Orthop Res 2006, 24:254-262.

8. Schutze N, Noth U, Schneidereit J, Hendrich C, Jakob F: Differential expression of $\mathrm{CCN}$-family members in primary human bone marrowderived mesenchymal stem cells during osteogenic, chondrogenic and adipogenic differentiation. Cell Commun Signal 2005, 3:5.

9. Schutze N, Schenk R, Fiedler J, Mattes T, Jakob F, Brenner RE: CYR61/CCN and WISP3/CCN6 are chemoattractive ligands for human multipotent mesenchymal stroma cells. BMC Cell Biol 2007, 8:45.

10. Lau LF: CCN1/CYR61: the very model of a modern matricellular protein. Cell Mol Life Sci 2011, 68:3149-3163.

11. Lau LF, Lam SC: The CCN family of angiogenic regulators: the integrin connection. Exp Cell Res 1999, 248:44-57.

12. Bleau AM, Planque N, Perbal B: CCN proteins and cancer: two to tango. Front Biosci 2005, 10:998-1009.

13. Dhar A, Ray A: The CCN family proteins in carcinogenesis. Exp Oncol 2010, $32: 2-9$.

14. Chong HC, Tan CK, Huang RL, Tan NS: Matricellular proteins: a sticky affair with cancers. J Oncol 2012, 2012:351089.

15. Perbal B: Alternative splicing of CCN mRNAs .... it has been upon us. I Cell Commun Signal 2009, 3:153-157. 
16. Bonomi S, Gallo S, Catillo M, Pignataro D, Biamonti G, Ghigna C: Oncogenic alternative splicing switches: role in cancer progression and prospects for therapy. Int J Cell Biol 2013, 2013:962038.

17. Hirschfeld M, Jaeger M, Buratti E, Stuani C, Grueneisen J, Gitsch G, Stickeler E: Expression of tumor-promoting Cyr61 is regulated by hTRA2-beta1 and acidosis. Hum Mol Genet 2011, 20:2356-2365.

18. Hirschfeld M, Zur Hausen A, Bettendorf H, Jager M, Stickeler E: Alternative splicing of Cyr61 is regulated by hypoxia and significantly changed in breast cancer. Cancer Res 2009, 69:2082-2090.

19. Palumbo A, Anderson K: Multiple myeloma. N Engl J Med 2011, 364:1046-1060.

20. Dolloff NG, Talamo G: Targeted therapy of multiple myeloma. Adv Exp Med Biol 2013, 779:197-221.

21. Roodman GD: Pathogenesis of myeloma bone disease. Blood Cells Mol Dis 2004, 32:290-292.

22. Marie PJ: Signaling pathways affecting skeletal health. Curr Osteoporos Rep 2012, 10:190-198.

23. Abu-Amer Y: NF-kappaB signaling and bone resorption. Osteoporos Int 2013, 24:2377-2386.

24. Roodman GD: Mechanisms of bone metastasis. N Engl J Med 2004, 350:1655-1664.

25. Hofbauer LC, Rachner TD, Coleman RE, Jakob F: Endocrine aspects of bone metastases. The Lancet Diab Endocrinol 2014, 2:500-512.

26. Terpos E, Kastritis E, Christoulas D, Gkotzamanidou M, EleutherakisPapaiakovou E, Kanellias N, Papatheodorou A, Dimopoulos MA: Circulating activin-A is elevated in patients with advanced multiple myeloma and correlates with extensive bone involvement and inferior survival; no alterations post-lenalidomide and dexamethasone therapy. Ann Oncol 2012, 23:2681-2686

27. Gkotzamanidou M, Dimopoulos MA, Kastritis E, Christoulas D, Moulopoulos $L A$, Terpos E: Sclerostin: a possible target for the management of cancerinduced bone disease. Expert Opin Ther Targets 2012, 16:761-769.

28. Kaiser MF, Heider U, Mieth M, Zang C, von Metzler I, Sezer O: The proteasome inhibitor bortezomib stimulates osteoblastic differentiation of human osteoblast precursors via upregulation of vitamin $D$ receptor signalling. Eur J Haematol 2013, 90:263-272.

29. Qiang YW, Heuck CJ, Shaughnessy JD Jr, Barlogie B, Epstein J: Proteasome inhibitors and bone disease. Semin Hematol 2012, 49:243-248.

30. Longo V, Brunetti O, D'Oronzo S, Dammacco F, Silvestris F: Therapeutic approaches to myeloma bone disease: an evolving story. Cancer Treat Rev 2012, 38:787-797.

31. Terpos E, Kastritis E, Dimopoulos MA: Prevention and treatment of myeloma bone disease. Curr Hematol Malig Rep 2012, 7:249-257.

32. Pozzi S, Fulciniti M, Yan H, Vallet S, Eda H, Patel K, Santo L, Cirstea D, Hideshima T, Schirtzinge L, Kuhstoss S, Anderson KC, Munshi N, Scadden D, Kronenberg HM, Raje N: In vivo and in vitro effects of a novel anti-Dkk1 neutralizing antibody in multiple myeloma. Bone 2013, 53:487-496.

33. Chantry AD, Heath D, Mulivor AW, Pearsall S, Baud'huin M, Coulton L, Evans $\mathrm{H}$, Abdul N, Werner ED, Bouxsein ML, Key ML, Seehra J, Arnett TR, Vanderkerken $\mathrm{K}$, Croucher $\mathrm{P}$ : Inhibiting activin-A signaling stimulates bone formation and prevents cancer-induced bone destruction in vivo. J Bone Miner Res 2010, 25:2633-2646.

34. Reagan MR, Ghobrial IM: Multiple myeloma mesenchymal stem cells: characterization, origin, and tumor-promoting effects. Clin Cancer Res 2012, 18:342-349.

35. Xu S, Evans H, Buckle C, De Veirman K, Hu J, Xu D, Menu E, De Becker A, Vande Broek I, Leleu X, Camp BV, Croucher P, Vanderkerken K, Van Riet I: Impaired osteogenic differentiation of mesenchymal stem cells derived from multiple myeloma patients is associated with a blockade in the deactivation of the Notch signaling pathway. Leukemia 2012, 26:2546-2549

36. Corre J, Labat E, Espagnolle N, Hebraud B, Avet-Loiseau H, Roussel M, Huynh A, Gadelorge M, Cordelier P, Klein B, Moreau P, Facon T, Fournié JJ, Attal M, Bourin P: Bioactivity and prognostic significance of growth differentiation factor GDF15 secreted by bone marrow mesenchymal stem cells in multiple myeloma. Cancer Res 2012, 72:1395-1406

37. Li X, Ling W, Khan S, Yaccoby S: Therapeutic effects of intrabone and systemic mesenchymal stem cell cytotherapy on myeloma bone disease and tumor growth. J Bone Miner Res 2012, 27:1635-1648.

38. Chatterjee M, Honemann D, Lentzsch S, Bommert K, Sers C, Herrmann P, Mathas S, Dorken B, Bargou RC: In the presence of bone marrow stromal cells human multiple myeloma cells become independent of the IL-6/ gp130/STAT3 pathway. Blood 2002, 100:3311-3318.

39. Pfaffl MW, Horgan GW, Dempfle L: Relative expression software tool (REST) for group-wise comparison and statistical analysis of relative expression results in real-time PCR. Nucleic Acids Res 2002, 30:e36.

40. Tanaka F, Rizqiawan A, Higashikawa K, Tobiume K, Okui G, Shigeishi H, Ono S, Shimasue H, Kamata N: Snail promotes Cyr61 secretion to prime collective cell migration and form invasive tumor nests in squamous cell carcinoma. Cancer Lett 2012, 329:243-52.

41. Lau LF, Tam SC: Integrin-Mediated CCN Functions. In CCN Protein: A New Family of Cell Growth and Differentiation Regulators. Edited by Perbal B, Takigawa M. London: Imperial College Press; 2005:61-79.

42. Ruoslahti E: RGD and other recognition sequences for integrins. Annu Rev Cell Dev Biol 1996, 12:697-715.

43. Katz BZ: Adhesion molecules-The lifelines of multiple myeloma cells. Semin Cancer Biol 2010, 20:186-195.

44. Harris LG, Pannell LK, Singh S, Samant RS, Shevde LA: Increased vascularity and spontaneous metastasis of breast cancer by hedgehog signaling mediated upregulation of cyr61. Oncogene 2012, 31:3370-3380.

45. Liu H, Yang R, Tinner B, Choudhry A, Schutze N, Chaqour B: Cysteine-rich protein 61 and connective tissue growth factor induce deadhesion and anoikis of retinal pericytes. Endocrinology 2008, 149:1666-1677.

46. Santra M, Shaughnessy JD Jr, Bellamy WT: Expression of multiple myeloma associated markers in bone marrow spicules using a novel immunohistochemical technique. Biotech Histochem 2011, 86:119-123.

47. Lin J, Huo R, Wang L, Zhou Z, Sun Y, Shen B, Wang R, Li N: A novel antiCyr61 antibody inhibits breast cancer growth and metastasis in vivo. Cancer Immunol Immunother 2012, 61:677-687.

48. Schmitz P, Gerber U, Jungel E, Schutze N, Blaheta R, Bendas G: Cyr61/CCN1 affects the integrin-mediated migration of prostate cancer cells (PC-3) in vitro. Int J Clin Pharmacol Ther 2013, 51:47-50

49. Yang GP, Lau LF: Cyr61, product of a growth factor-inducible immediate early gene, is associated with the extracellular matrix and the cell surface. Cell Growth Differ 1991, 2:351-357.

50. Giuliani N, Storti P, Bolzoni M, Palma BD, Bonomini S: Angiogenesis and multiple myeloma. Cancer Microenviron 2011, 4:325-337.

51. Leu SJ, Liu Y, Chen N, Chen CC, Lam SC, Lau LF: Identification of a novel integrin alpha 6 beta 1 binding site in the angiogenic inducer CCN1 (CYR61). J Biol Chem 2003, 278:33801-33808.

52. Burger R, Guenther A, Bakker F, Schmalzing M, Bernand S, Baum W, Duerr B, Hocke GM, Steininger H, Gebhart E, Gramatzki M: Gp130 and ras mediated signaling in human plasma cell line INA-6: a cytokine-regulated tumor model for plasmacytoma. Hematol J 2001, 2:42-53.

53. Klopp AH, Gupta A, Spaeth E, Andreeff M, Marini F 3rd: Concise review: Dissecting a discrepancy in the literature: do mesenchymal stem cells support or suppress tumor growth? Stem Cells 2011, 29:11-19.

54. Terpos E, Christoulas D, Katodritou E, Bratengeier C, Gkotzamanidou M, Michalis E, Delimpasi S, Pouli A, Meletis J, Kastritis E, Zervas K, Dimopoulos MA: Elevated circulating sclerostin correlates with advanced disease features and abnormal bone remodeling in symptomatic myeloma: reduction post-bortezomib monotherapy. Int J Cancer 2012, 131:1466-1471.

55. Vallet $S$, Mukherjee S, Vaghela N, Hideshima T, Fulciniti M, Pozzi S, Santo L, Cirstea D, Patel K, Sohani AR, Guimaraes A, Xie W, Chauhan D, Schoonmaker JA, Attar E, Churchill M, Weller E, Munshi N, Seehra JS, Weissleder R, Anderson KC, Scadden DT, Raje N: Activin A promotes multiple myelomainduced osteolysis and is a promising target for myeloma bone disease. Proc Natl Acad Sci U S A 2010, 107:5124-5129.

56. Noth U, Osyczka AM, Tuli R, Hickok NJ, Danielson KG, Tuan RS: Multilineage mesenchymal differentiation potential of human trabecular bonederived cells. J Orthop Res 2002, 20:1060-1069.

57. Schutze N, Kunzi-Rapp K, Wagemanns R, Noth U, Jatzke S, Jakob F: Expression, purification, and functional testing of recombinant CYR61/ CCN1. Protein Expr Purif 2005, 42:219-225.

\section{doi:10.1186/1478-811X-12-36}

Cite this article as: Dotterweich et al:: Mesenchymal stem cell contact promotes CCN1 splicing and transcription in myeloma cells. Cell Communication and Signaling 2014 12:36. 